\title{
Using Bio-Layer Interferometry to Evaluate Anti-PEG Antibody-Mediated Complement Activation
}

\author{
Mahmoud Mostafa, ${ }^{a, b}$ Nehal E. Elsadek, ${ }^{a}$ Sherif E. Emam, ${ }^{a, c}$ Hidenori Ando, ${ }^{a}$ Taro Shimizu, ${ }^{a}$ \\ Hamdy Abdelkader, ${ }^{b, d}$ Yu Ishima,${ }^{a}$ Usama Farghaly Aly ${ }^{b}$ Hatem A. Sarhan,${ }^{b}$ and \\ Tatsuhiro Ishida*,a \\ ${ }^{a}$ Department of Pharmacokinetics and Biopharmaceutics, Institute of Biomedical Sciences, Tokushima University; \\ 1-78-1 Sho-machi, Tokushima 770-8505, Japan: ${ }^{b}$ Department of Pharmaceutics, Faculty of Pharmacy, Minia \\ University; Minia 61519, Egypt: ${ }^{c}$ Department of Pharmaceutics and Industrial Pharmacy, Faculty of Pharmacy, \\ Zagazig University; Zagazig 44519, Egypt: and ${ }^{d}$ Department of Pharmaceutics, Deraya University; New Minia 61768, \\ Egypt.
}

Received September 7, 2021; accepted October 30, 2021

The purpose of this study was to develop a Bio-layer interferometry (BLI) system that could be an alternative approach for the direct evaluation of anti-polyethylene glycol (PEG) immunoglobulin M (IgM)-mediated complement activation of the accelerated blood clearance (ABC) phenomenon. Complement activation is well known to play an important role in the clearance of PEGylated and non-PEGylated nanomedicines following intravenous injection. This complement system is also thought to be responsible for the $\mathrm{ABC}$ phenomenon wherein repeated injections of PEGylated products are bound by anti-PEG antibodies. This study used three different sources of anti-PEG antibodies: HIK-M09 monoclonal antibodies (mAbs); HIK-M11 mAbs; and antiserum containing polyclonal anti-PEG IgMs. 1,2-Distearoyl-sn-glycero3-phosphoethanolamine- $n$-[methoxy (polyethylene glycol)-2000] (mPEG ${ }_{2000}$-DSPE) was immobilized as an antigen on aminopropyl silane biosensor chips of BLI. All anti-PEG IgMs in the sources increased the signals (thickness of the layer around the sensor tip) regarding binding of anti-PEG antibodies to PEG on the chips. In all anti-PEG IgM sources, further increases in the signals were observed when incubated in naïve mouse serum, which is a complement source, but not in heat inactivated $\left(56^{\circ} \mathrm{C}, 30 \mathrm{~min}\right)$ mouse serum, which abolishes complement activity. These findings show that the complement activation mediated via anti-PEG IgMs, which occurred on the sensor chips, was detected via BLI analysis. The complement activation induced by all anti-PEG IgM sources was confirmed via conventional enzyme-linked immunosorbent assay (ELISA), which is the conventional mode for detection of complement activation. Our study results show that BLI is a simple alternative method for the detection of complement activation.

Key words bio-layer interferometry; polyethylene glycol (PEG); anti-PEG immunoglobulin M (IgM); accelerated blood clearance $(\mathrm{ABC})$ phenomenon; complement activation

\section{INTRODUCTION}

The complement system plays an important role in the clearance of PEGylated and non-PEGylated nanomedicines after intravenous injection (IV). ${ }^{1-4)}$ In addition, complement activation by PEGylated products represents a potential hazard in an initiation of immune adverse effects such as infusion reactions and complement activation-related pseudo allergies. ${ }^{5}$ Furthermore, complement activation is responsible for the accelerated blood clearance (ABC) phenomenon that affects PEGylated products via the binding of anti-polyethylene glycol (PEG) antibodies to PEGylated products. ${ }^{2,6-8)}$ Accordingly, the screening of complement activation and the measure of its extent are of pivotal importance for predicting the in vivo fate of administered PEGylated products, as well as for safety issues.9) Currently, several methods to detect complement activation such as Western blotting, ${ }^{10,11)}$ enzyme-linked immunosorbent assay (ELISA), ${ }^{9,10,12,13)}$ and complement hemolysis ${ }^{14,15)}$ are available. Although these methods are convenient and easy to conduct, there are disadvantages. ELISA is a lengthy and relatively expensive process with a high probability of false positive or negative results. ${ }^{16)}$ The principle of ELISA depends mainly on the labeling of proteins or antibodies that could alter the protein activity and/or efficiency. ${ }^{17,18)}$ Complement hemolysis is generally less sensitive. ${ }^{19)}$ Western blotting is another lengthy and tedious procedure. ${ }^{20)}$ The drawbacks of these methods have encouraged the development of additional or alternative methods to detect/measure complement activation.

Label-free methods have shown utility in the detection, characterization, and analysis of several biomolecular interactions. These methods include, but are not limited to, surface plasmon resonance and acoustic measurements. ${ }^{21,22)}$ Bio-layer interferometry (BLI) is a promising technique that enables the detection of antigen-antibody interactions in a simple, rapid, on-time, label-free, and reproducible manner that features accurate and precise calculation of the affinity and kinetics constants. $^{23,24)}$ BLI is an optical system that can be used to analyze the interference pattern between two layers located on a biosensor: the internal reference layer and the ligand immobilization layer. ${ }^{23)}$ The thickness of the biological layer around the sensor chip correlates with the interferometric pattern of the length of waves. ${ }^{23)}$ The biomolecular interaction between an analyte and an immobilized ligand increases the thickness of the biological layer around the optical fiber sensor and results in a shift in the wavelength of the reflected light wherein the response can be recorded using a detector. ${ }^{17)} \mathrm{A}$ 
change of $1 \mathrm{~nm}$ in the mass thickness around the biosensor tip results in a shift of $1 \mathrm{~nm}$ in the interferometric wave pattern. ${ }^{25}$ ) This positive shift is the result of the attachment of molecules to the biosensor tip as the thickness of the biological layer increases. Samples were kept under continuous orbital rotation to bypass the potential direct effect of diffusion during the kinetic analysis. ${ }^{26)}$

In this study, we intended to use the BLI ForteBio Octet ${ }^{\circledR}$ system to develop an alternative method that could detect the mediated complement activation of anti-PEG antibodies in real time. The results obtained via BLI were comparable to those obtained using the conventional ELISA method under the same conditions.

\section{MATERIALS AND METHODS}

Materials Hydrogenated egg phosphatidylcholine (HEPC) and 1,2-distearoyl-sn-glycero-3-phosphoethanolamine- $n$ [methoxy (polyethylene glycol)-2000] ( $\mathrm{mPEG}_{2000}$-DSPE) were purchased from NOF (Tokyo, Japan). Cholesterol (Chol) was purchased from FUJIFILM Wako Pure Chemical Corporation (Osaka, Japan). All other reagents were of analytical grade.

Animals BALB/c mice (female, 5 weeks old) were purchased from Japan SLC (Shizuoka, Japan). The experimental animals were allowed free access to water and mouse chow, and were housed under controlled environmental conditions (constant temperature and humidity, and a 12-h dark-light cycle). All animal experiments were evaluated and approved by the Animal and Ethics Review Committee of Tokushima University (T2019-47).

Anti-PEG Immunoglobulin M (IgM) Monoclonal Antibodies (HIK-M09 and HIK-M11 mAbs) Anti-PEG IgM monoclonal antibodies (mAbs), HIK-M09 and HIK-M11 mAbs, were obtained from the culture media of hybridoma cells (HIK-M09 cells and HIK-M11 cells). These hybridomas were previously developed in our laboratory via immunizations into BALB/c mice by either IV with empty PEGylated liposomes or subcutaneous injections of PEGylated ovalbumin, respectively. ${ }^{10)}$ Briefly, each hybridoma was cultured in RPMI-1640 medium (FUJIFILM Wako Pure Chemical Corporation) containing $10 \%$ heat inactivated fetal bovine serum (COSMO BIO, Tokyo, Japan), $100 \mathrm{IU} / \mathrm{mL}$ penicillin, and $100 \mu \mathrm{g} / \mathrm{mL}$ streptomycin (ICN Biomedicals, CA, U.S.A.) at $37^{\circ} \mathrm{C}$ in an air incubator under $5 \% \mathrm{CO}_{2}$. At $50 \%$ confluence, the culture media were centrifuged $(5 \mathrm{~min}, 300 \times \boldsymbol{g}$, $4{ }^{\circ} \mathrm{C}$ ) to collect the supernatant. A concentration of the supernatants and medium replacement with phosphate buffered saline (PBS) was achieved using $100 \mathrm{KDa}$ Amicon ${ }^{\circledR}$ Ultra-15 centrifugal filters (Merck Millipore, Cork, Ireland). The concentration of $\mathrm{mAbs}$ in the obtained solution was determined via ELISA. ${ }^{27)}$ A standard calibration curve for both $\mathrm{mAbs}$ was prepared using standard (purified) HIK-M09 or HIK-M11 mAbs, which was obtained by culturing the hybridoma cells in protein-free/serum-free, chemically defined medium (Thermo Fisher Scientific, CA, U.S.A.).

Antiserum Containing Polyclonal Anti-PEG IgMs BALB/c mice were immunized with a single IV injection of empty PEGylated liposomes $(0.1 \mu \mathrm{mol}$ phospholipids $/ \mathrm{kg})$. On Day 5, anti-PEG antiserum (serum containing anti-PEG antibodies) was prepared after blood collection from the inferior vena cava. The antiserum was checked for anti-PEG antibodies titer and used in its fresh state for further experiments. ${ }^{28)}$ A simple ELISA method was used to detect and determine the titer of anti-PEG IgM antibodies, as previously reported. ${ }^{29)}$ Empty PEGylated liposomes (HEPC: Chol: $\mathrm{mPEG}_{2000^{-}}$ $\mathrm{DSPE}=1.85: 1: 0.15(\mathrm{~mol} / \mathrm{mol}))$ were prepared using thin film extrusion, as previously reported. ${ }^{30)}$ The mean diameter $(109 \pm 13 \mathrm{~nm})$ and zeta potential $(-6.5 \pm 1.7 \mathrm{mV})$ of the prepared liposomal systems were checked using a Zetasizer Nano (Malvern Ltd., U.K.). Phospholipid concentration (16.6mM) was determined using a Bartlett colorimetric assay. ${ }^{31)}$

BLI Analysis for Interactions of Anti-PEG Abs to the PEG of $\mathbf{m P E G}_{\mathbf{2 0 0 0}}$-DSPE An Octet ${ }^{\circledR}$ Red 96 system $^{\circledR}$ (ForteBio, CA, U.S.A.) was used to detect interactions between anti-PEG antibodies and $\mathrm{mPEG}_{2000}$-DSPE using aminopropyl silane (APS) biosensors (Fig. 1A) according to the standard instructions with minor modifications. APS biosensors were chosen because they are appropriate for lipid loading. ${ }^{32)}$ Black 96-well plates (Greiner Bio-One International $\mathrm{GmbH}$, Frickenhausen, Germany) were used for all assays. APS sensors were pre-wetted with PBS for at least $10 \mathrm{~min}$ before each assay. The running volume for all samples or buffers was $200 \mu \mathrm{L}$. The rpm option and plate temperature were kept at $1000 \mathrm{rpm}$ and $37^{\circ} \mathrm{C}$, respectively, for the entire assay. First, APS biosensors were equilibrated with PBS for $60 \mathrm{~s}$ followed by immobilization of the $\mathrm{mPEG}_{2000}$-DSPE ( $140 \mathrm{nM}$ in PBS, $300 \mathrm{~s})$. The sensors were then blocked using $1 \%$ bovine serum albumin (BSA) in PBS for $300 \mathrm{~s}$ to prevent nonspecific binding. Then, the association of anti-PEG IgMs was recorded for $4000 \mathrm{~s}$. Three types of anti-PEG IgMs were used: HIK-M09 $\mathrm{mAbs}(150 \mu \mathrm{g} / \mathrm{mL})$, HIK-M11 mAbs $(150 \mu \mathrm{g} / \mathrm{mL})$, and heatinactivated anti-PEG antiserum $(5 \%(\mathrm{v} / \mathrm{v}))$. The dissociation step was performed in PBS for $900 \mathrm{~s}$.

BLI Analysis for the Mediated Complement Activation of Anti-PEG IgMs Procedures similar to those described above were followed except for the association step. The association step was performed under the following conditions: only HIK-M09 mAbs $(150 \mu \mathrm{g} / \mathrm{mL})$ and only HIK-M11 mAbs $(150 \mu \mathrm{g} / \mathrm{mL})$; separate samples of untreated naïve mouse serum (source of complement components) and heat-inactivated serum $(5 \%(\mathrm{v} / \mathrm{v})$, final concentrations) with additions of HIK-M09 $(150 \mu \mathrm{g} / \mathrm{mL})$ and HIK-M11 mAbs $(150 \mu \mathrm{g} / \mathrm{mL})$, respectively; either untreated or heat-inactivated anti-PEG antiserum $(5 \%(\mathrm{v} / \mathrm{v}))$; and, untreated naïve mice serum $(5 \%(\mathrm{v} / \mathrm{v}))$ without the addition of anti-PEG antibodies (Control).

ELISA Detection of the Mediated Complement Activation of Anti-PEG IgMs ELISA samples were prepared in a manner similar to that of BLI, as follows: either untreated or heat-inactivated mouse serum $(5 \%(\mathrm{v} / \mathrm{v}))$ was diluted with gelatin veronal buffer $\left(\mathrm{GVB}^{2+} ; 2.5 \mathrm{mM}\right.$ veronal buffer; $\mathrm{pH}$ 7.3, $70 \mathrm{mM} \mathrm{NaCl}, 0.1 \%$ gelatin, $1 \mathrm{mM} \mathrm{MgCl}_{2}, 0.15 \mathrm{mM} \mathrm{CaCl} 2$ ) with the addition of either HIK-M09 or HIK-M11 mAbs $(150 \mu \mathrm{g} / \mathrm{mL})$. Also, either untreated or heat-inactivated antiserum $(5 \% \mathrm{v} / \mathrm{v})$ containing polyclonal anti-PEG IgMs was diluted with $\mathrm{GVB}^{2+}$. Naïve mice serum that was either untreated or heat inactivated $(5 \%(\mathrm{v} / \mathrm{v}))$ without the addition of anti-PEG antibodies served as negative controls for mAbs, while heat inactivated antiserum $(5 \%(\mathrm{v} / \mathrm{v}))$ served as a negative control for the untreated mouse antiserum. Heat inactivation was accomplished via the incubation of sera at $56^{\circ} \mathrm{C}$ for $30 \mathrm{~min}$ to abolish the complement activity. ${ }^{33)}$

The complement component of $\mathrm{C} 3$ deposition is an indica- 
(A)
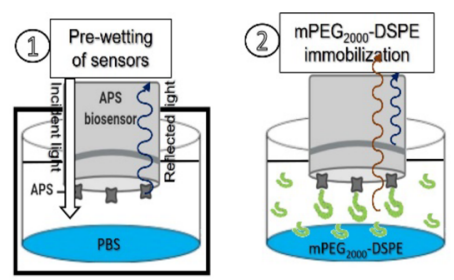

PBS
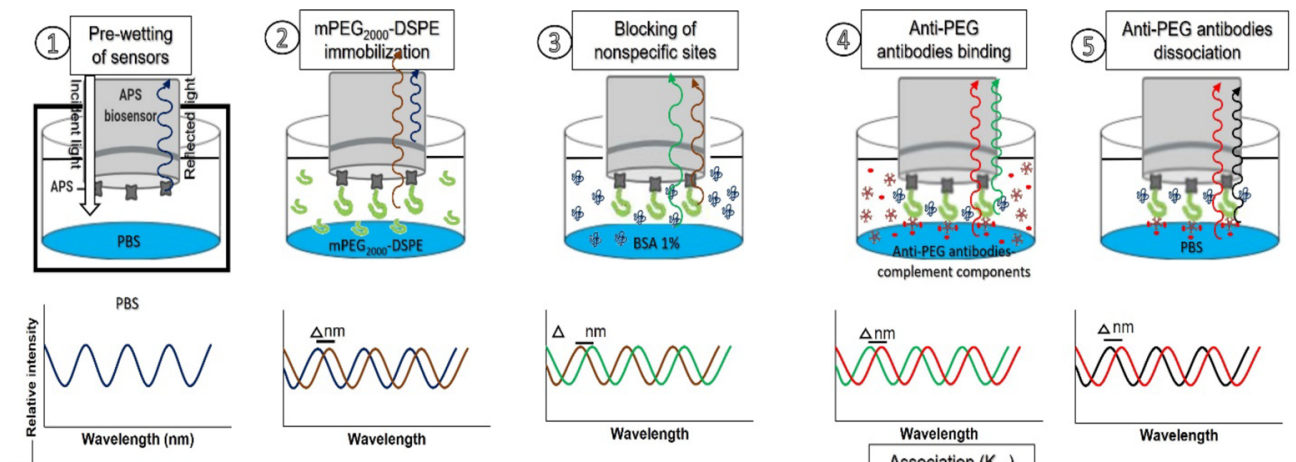

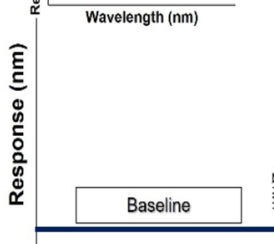

Association $\left(\mathrm{K}_{\mathrm{o}}\right)$

Dissociation $\left(\mathrm{K}_{\mathrm{off}}\right)$

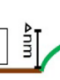

$2^{\text {nd }}$ Baseline
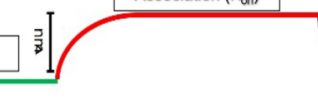

Time (sec)

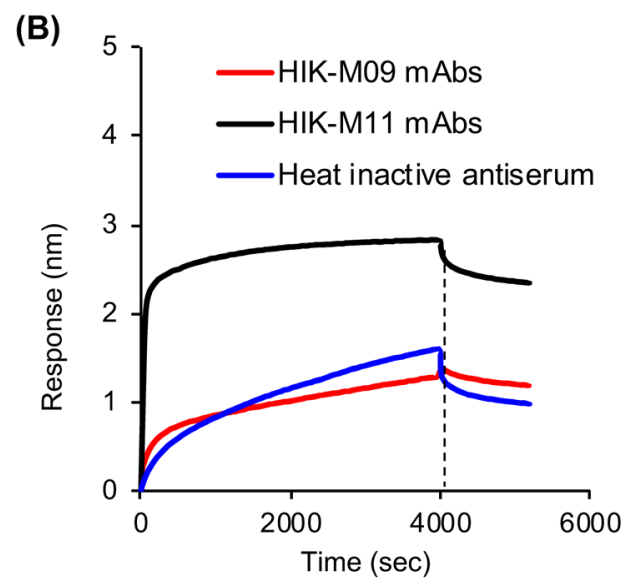

Fig. 1. BLI Analysis for Anti-PEG IgMs Binding to PEG

(A) The BLI technique is dependent on analysis of the interference pattern of light reflected from both the reference layer and the immobilized layer on the sensor tip. The binding of molecules to the sensor tip alters that pattern and cause a shift in the wavelength $(\triangle K)$, which is correlated with the thickness of the biological layer on the sensor tip. This process occurs in real time using the ForteBio octet system. Sensors were first equilibrated in PBS then loaded with ligand (mPEG $\mathrm{m}_{2000}-\mathrm{DSPE}$ ). Nonspecific sites were blocked with PBS containing 1\% BSA followed by association with the analyte (anti-PEG antibodies). (B) Sensors were first loaded with mPEG ${ }_{200}$-DSPE followed by association with the three tested anti-PEG antibodies (HIK-M09, HIK-M11 mAbs and antiserum containing polyclonal anti-PEG antibodies). Each sensorgram represents at least five independent experiments. (Color figure can be accessed in the online version.)

tor of complement activation, and to detect it a simple previously developed ELISA procedure was employed with minor modification. ${ }^{9,13)}$ Briefly, the wells of a 96-well plate were coated with $0.5 \mathrm{nmol} \mathrm{mPEG}_{2000}-\mathrm{DSPE}$ in ethanol $(50 \mu \mathrm{L})$ and left to evaporate overnight. The plate was then blocked with PBS containing 1\% BSA for $1 \mathrm{~h}(200 \mu \mathrm{L})$ and was then washed 3 times with PBS containing $0.1 \%$ Tween 20 . Samples $(100 \mu \mathrm{L})$ were added to the wells and incubated for $30 \mathrm{~min}$ at $37^{\circ} \mathrm{C}$. After 5 wash cycles, C3 deposition, as a result of complement activation, was detected using horseradish peroxidase (HRP) conjugated goat anti-mouse C3 (Immunology Consultants Laboratory, OR, U.S.A.) (100 $\mu \mathrm{L}, 1$ : 10000). Colorization was carried out by the addition of $100 \mu \mathrm{L}$ of o-phenylenediamine (OPD) for $15 \mathrm{~min}$ at room temperature. The reaction was stopped by the addition of $2 \mathrm{M}$ of sulfuric acid $(100 \mu \mathrm{L})$. The absorbance was measured at $492 \mathrm{~nm}$ using a microplate reader (infinite M200, TECAN Japan, Kanagawa, Japan).

Data and Statistical Analyses The data obtained were fitted globally to a $1: 2$ bivalent analyte model to calculate the rate and affinity constants using Octet ${ }^{\circledR}$ system data analysis software (version 7.1, ForteBio). All values are expressed as the mean \pm standard deviation (S.D.) Statistical analysis was carried out via either an unpaired $t$-test for groups of less than three or an ANOVA test for three or more groups using Graphpad Prism 6.01 software (GraphPad Software Inc., CA, U.S.A.). The level of significance was set at $* * p<0.01$ and *** $p<0.001$.

\section{RESULTS}

BLI Analysis for Binding of Anti-PEG IgMs to PEG The BLI analysis involved four steps: equilibration of sensors, ligand (antigen) immobilization to sensors, analyte association, and analyte dissociation (Fig. 1A). The amount of ligand immobilization fully influenced the analysis. ${ }^{17)}$ Therefore, through the use of different concentrations of $\mathrm{mPEG}_{2000^{-}}$ DSPE, $140 \mathrm{nM}$ of $\mathrm{mPEG}_{2000}$-DSPE was finally selected based on the least concentration of the immobilized ligand 
that would produce an adequate association with the analyte (monoclonal anti-PEG IgMs) in the association step (data not shown). A typical immobilization step with $\mathrm{mPEG}_{2000}$-DSPE slightly increased the loading signal by 0.4 to $0.8 \mathrm{~nm}$, which was subtracted in the data analysis. When HIK-M09 mAbs were tested, the signal was rapidly increased to $0.8 \mathrm{~nm}$ at the onset of the interaction between antibodies and PEG, and then the signal was gradually increased to $1.6 \mathrm{~nm}$ during the entire incubation period $(4000 \mathrm{~s})$ (Fig. 1B). In HIK-M11 mAbs, the interaction was instantaneous, and the signal was also rapidly increased within only a few seconds to $2.2 \mathrm{~nm}$. A steady state was reached at $2.7 \mathrm{~nm}$ (Fig. 1B). Both the HIK-M09 and HIK-M11 mAbs appeared to rapidly bind to the immobilized PEG, albeit to a different extent. In the heat-inactivated antiPEG serum including anti-PEG IgMs, anti-PEG IgMs were also bound to the PEG with levels of speed and extent that

(A)
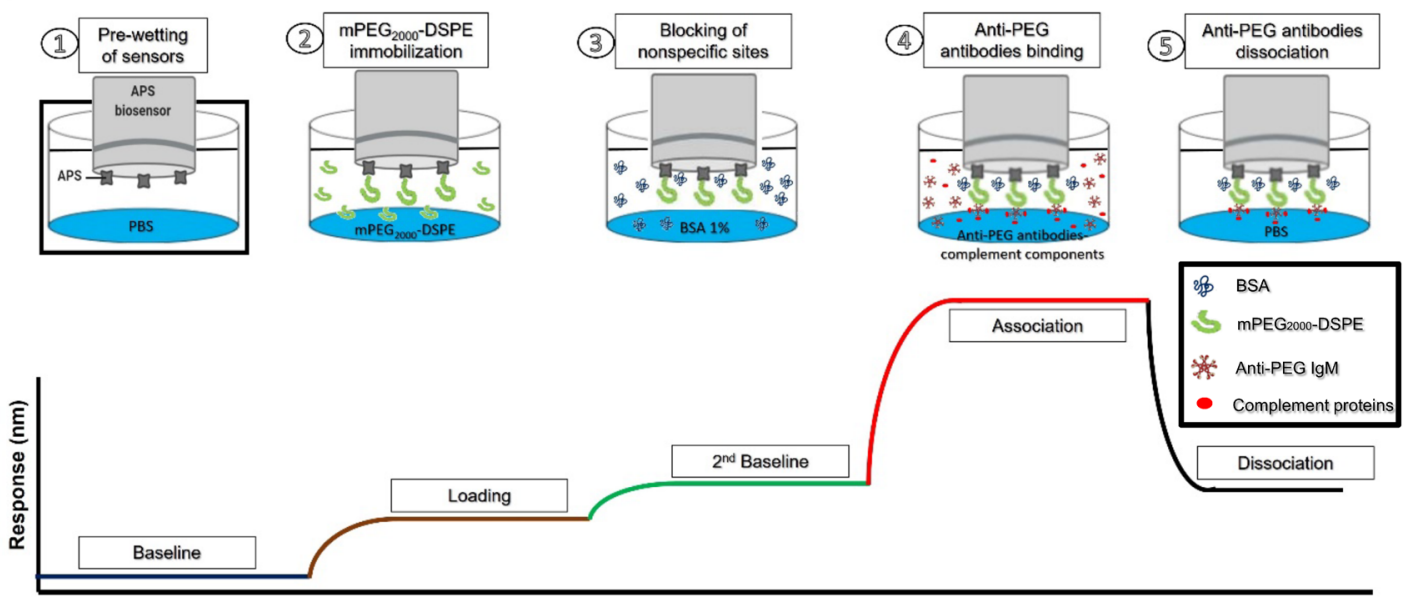

Time (sec)

(B)
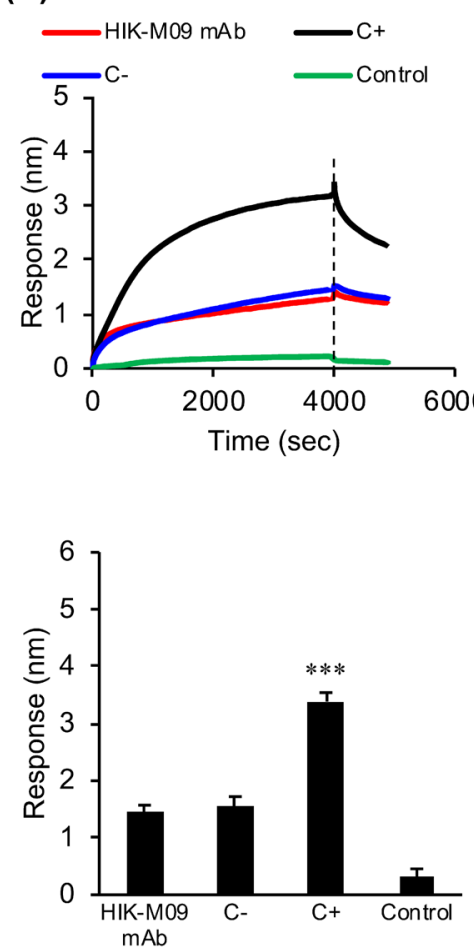

(C)
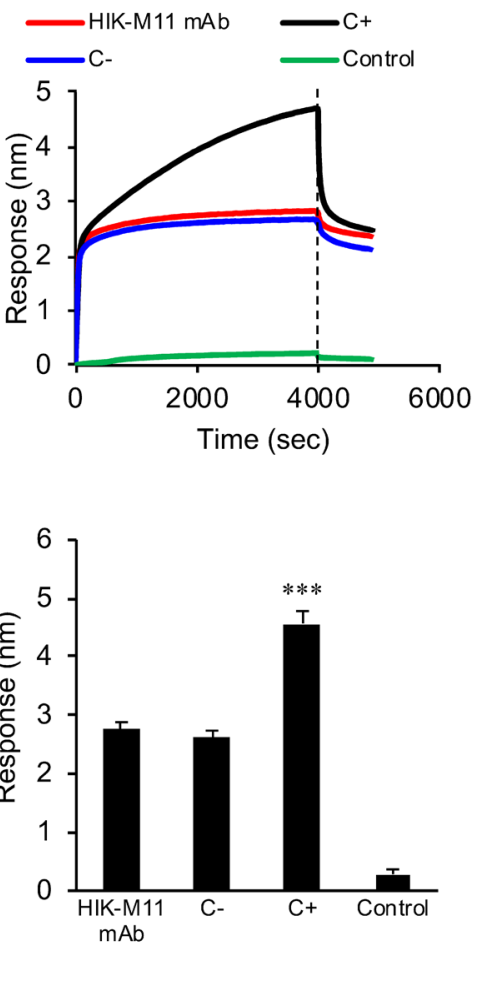

(D)
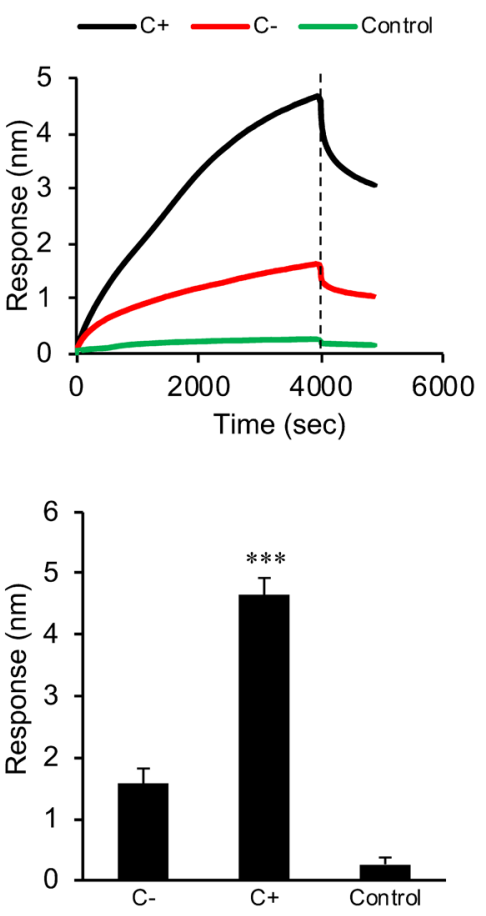

Fig. 2. BLI Analysis for the Mediated Activation of Anti-PEG IgM to the Complement System

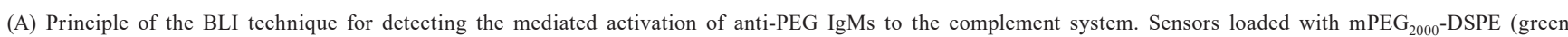
shapes) were incubated at $37^{\circ} \mathrm{C}$ with anti-PEG IgMs (pentagonal shapes) plus naïve mouse serum, which served as a complement source (red dots). Attachment of immune complexes (anti-PEG IgMs and complement components) to the sensors increased the thickness of the sensor biological layer and shifted the reflected light wavelength to a higher signal compared with the antibodies alone. (B-D) The typical binding sensorgrams and capture levels. (B) Only HIK-M09 mAbs (150 $\mu$ g/mL), HIK-M09 mAbs with untreated naïve mice serum $(\mathrm{C}+)$, HIK-M09 with heat-inactivated naïve mice serum $(\mathrm{C}-)$, only naïve mice serum (Control). (C) Only HIK-M11 mAbs (150 $\mu$ g/mL), HIK-M11 mAbs with untreated naïve mice serum (C+), HIK-M11 mAbs with heat-inactivated naïve mice serum (C-), only naïve mice serum (Control). (D) Anti-PEG antiserum $(\mathrm{C}+)$, heat-inactivated anti-PEG antiserum $(\mathrm{C}-$ ), only naïve mice serum (Control). Each sensorgram is a representative of at least five independent experiments $(n=5)$. (Color figure can be accessed in the online version.) 
(A)

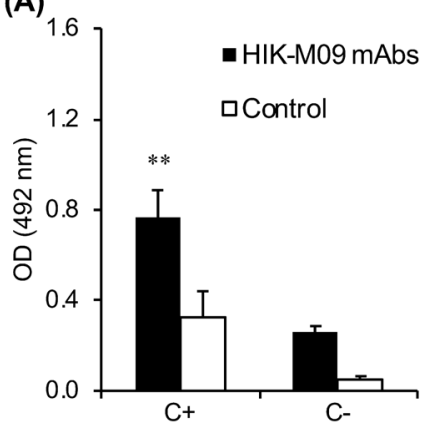

(B)

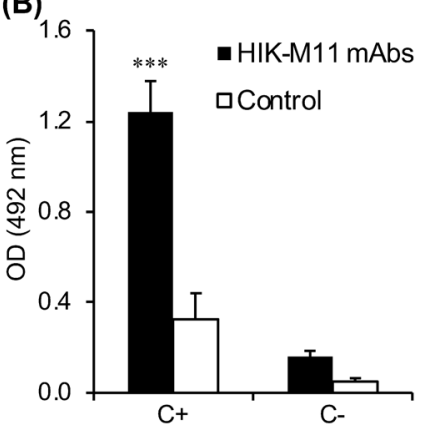

(C)

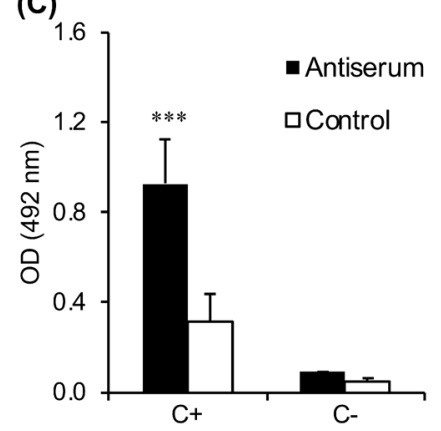

Fig. 3. Using ELISA to Detect Anti-PEG Antibody-Mediated Activation of the Complement System

Samples were incubated for $30 \mathrm{~min}$ at $37^{\circ} \mathrm{C}$ on a plate coated with $0.5 \mathrm{nmol} \mathrm{mPEG}{ }_{2000}$-DSPE. Then, C3 deposition was detected. (A) Either HIK-M09 mAbs or no mAbs $(\mathrm{Control})$ in either untreated $(\mathrm{C}+)$ or heat-inactivated $(\mathrm{C}-)$ naïve mice serum. $(\mathrm{B})$ Either HIK-M11 mAbs or no $\mathrm{mAbs}(\mathrm{control})$ in either untreated $(\mathrm{C}+)$ or heat-inactivated $(\mathrm{C}-)$ naïve mice serum. $(\mathrm{C})$ Either untreated antiserum $(\mathrm{C}+)$, heat inactivated $(\mathrm{C}-)$ antiserum or only naïve mouse serum $(\mathrm{Control})$. Each value represents the mean $\pm \mathrm{S} . \mathrm{D}$. $(n=6)$.

were similar to that of the HIK-M09 mAbs, reaching $1.6 \mathrm{~nm}$, but this was little more than antibody interaction with no complement activity.

BLI Analysis for Anti-PEG IgM-Mediated Complement Activation A complement is a system of more than 30 proteins in the plasma and on cell surfaces. ${ }^{34)}$ We have shown that complement activation mediated by anti-PEG IgMs occurs through a classical pathway as a part of the ABC phenomenon. ${ }^{9,10,13)}$ In the classical pathway, $\mathrm{Clq}$ binds to the $\mathrm{Fc}$ region of $\mathrm{IgMs}$ attached to pathogenic surfaces, then $\mathrm{C} 4 \mathrm{bC} 2 \mathrm{a}$ and $\mathrm{C} 3 \mathrm{~b}$ assembles with $\mathrm{Clq}-\mathrm{IgM}$ complexes, which results in larger immune complexes. ${ }^{34,35)}$

In the present study, therefore, we assumed that anti-PEG IgMs mediated the complement activation on the biosensor surfaces, and if this occurs it could be detected, because it would potentially increase the thickness of the biological layer around the biosensors and in turn increase the BLI signal to some extent (Fig. 2A). The typical binding sensorgrams and capture levels (mean \pm S.D.) are featured in Figs. 2B, 2C and 2D. HIK-M09 mAbs alone increased the capture level by approximately $1.6 \mathrm{~nm}$ (Fig. 2B, HIK-M09 mAbs), which is consistent with the results shown in Fig. 1B. The increased capture level was further increased to approximately $3.4 \mathrm{~nm}$ (2.4-fold) when naïve mice serum was added as a complement source (Fig. 2B, C+). But the increased capture level observed in HIK-M09 mAbs alone was not increased by the addition of heat-inactivated naïve mice serum in which complement activity was diminished (Fig. 2B, C-). HIK-M11 mAbs alone also increased the capture level by $2.7 \mathrm{~nm}$ (Fig. 2C, HIK-M11 $\mathrm{mAbs}$ ), which is consistent with the results shown in Fig. 1B. Similar to HIK-M09 mAbs, the increased capture level was further significantly increased to $4.6 \mathrm{~nm}$ (1.7-fold) when naïve mice serum was added (Fig. 2C, $\mathrm{C}+$ ). But the increased capture level observed in HIK-M11 mAbs alone was not increased by the addition of heat-inactivated naïve serum (Fig. 2C, C-), which is consistent with the results of HIK-M09 mAbs (Fig. 2B). Antiserum, which was inactivated to inhibit complement activation in the antiserum and contained only anti-PEG antibodies, increased the capture level by approximately $1.6 \mathrm{~nm}$ (Fig. 2D, C-), which agrees with the results shown in Fig. 1B. The increased signal was further significantly increased to $4.6 \mathrm{~nm}$ ( 2.8 folds) by using untreated anti-PEG antiserum $(\mathrm{C}+$ ), which possesses inherited complement activity (Fig. 2D, $\mathrm{C}+$ ). The level of capture was increased significantly with the use of untreated sera, which is consistent with the results obtained using HIK-M09 mAbs and HIK-M11 mAbs (Figs. 2B, C). Throughout all experiments, untreated naïve mice serum in the absence of anti-PEG IgMs (control) induced very few increases in capture levels and caused minimal interference (Figs. 2B-D, Control).

Complement Activation Mediated by Anti-PEG Antibodies Detected Using ELISA For comparison, the complement activation mediated by anti-PEG antibodies was detected in our laboratory using ELISA. ${ }^{9,10}$ The deposition of C3 fragments on the wells, was detected as a result of the binding by anti-PEG antibodies to immobilized $\mathrm{mPEG}_{2000}$-DSPE followed by complement activation via a classical pathway. In the HIK-M09 mAbs, C3 depositions were detected in the presence of naïve serum $(\mathrm{C}+)$ and in heat inactivated serum $(\mathrm{C}-$ ) (Fig. 3A). The $\mathrm{C} 3$ deposition levels were much higher in $\mathrm{C}+$ than that in $\mathrm{C}-$, meaning that anti-PEG IgM-mediated complement activation was obviously detected. In the HIK-M11 mAbs, C3 depositions were also detected in the presence of either naïve serum $(\mathrm{C}+)$ or heat-inactivated serum $(\mathrm{C}-)$ (Fig. 3B). The $\mathrm{C} 3$ deposition levels were much higher in $\mathrm{C}+$ than that in $\mathrm{C}-$ (Fig. 3B). Interestingly, the $\mathrm{C} 3$ deposition levels in HIK-M11 mAbs were 1.5-fold higher than those in HIK-M09 $\mathrm{mAbs}$, which is consistent with the capture levels observed in the BLI detection method shown in Figs. 2B and C. Untreated anti-PEG antiserum $(\mathrm{C}+)$, which is fully functional for complement activation, caused a much higher level of $\mathrm{C} 3$ deposition compared with that of heat-inactivated anti-PEG antiserum (C-) (Fig. 3C).

\section{DISCUSSION}

The principle of the ABC phenomenon of PEGylated products is based on the binding of anti-PEG antibodies to the PEG moiety of PEGylated products, which is followed by the initiation of complement activation., ${ }^{2,6-8,36}$ Over the past few years, BLI technology has become state-of-the-art in the field of biomolecular interaction detection and quantification. ${ }^{17,26)}$ In the present study, we optimized the use of BLI by replicating the mediated complement activation of anti-PEG antibodies on the biosensor tip of the BLI system. The biosensor tips were immobilized with $\mathrm{mPEG}_{2000}$-DSPE and then incubated with anti-PEG antibodies in the presence of a complement source (naïve mouse serum) (Fig. 2A). As we expected, BLI analysis 
showed an increase in the thickness of the biological layer (signals or capture levels) around the biosensor tip following incubations of samples with anti-PEG IgMs (Fig. 1B) and with anti-PEG IgMs containing a complement source $(\mathrm{C}+)$ (Figs. $2 \mathrm{~B}, \mathrm{C})$. On the other hand, such increases in the capture levels (signals) were not observed when heat-inactivated serum $(\mathrm{C}-$ ) was added instead of naïve serum (complement source $(\mathrm{C}+)$ ). Because heating serum at $56^{\circ} \mathrm{C}$ for $30 \mathrm{~min}$ is conventionally used to inactivate the complement system, ${ }^{37,38)}$ the observations from our experimental conditions clearly indicate that the binding of anti-PEG antibodies to immobilized PEG and subsequent complement activation occurred and was detected on the biosensor tips of the BLI system.

For comparison, the mediated complement activation of anti-PEG antibody was also detected using ELISA, ${ }^{10,13)}$ as shown in Fig. 3. Complement activation was confirmed in all anti-PEG IgMs when naïve serum (complement source $(\mathrm{C}+)$ ) was added (Fig. 3). The rank order of the extent of complement activation induced by each of the anti-PEG IgM sources (Fig. 3) approximated that measured via BLI analysis (Fig. 2). These observations support our hypothesis that the BLI analysis introduced in this study is an acceptable alternative for the detection and screening of antibody-mediated complement activation, and this method could be widely applied to detect complement activation via the antigen-antibody immune complex-mediated classical pathway.

In this study, we employed two different monoclonal antiPEG IgMs (HIK-M09 mAbs and HIK-M11 mAbs) that we had previously developed. ${ }^{10)}$ Their binding affinities to the PEG moiety and abilities to initiate complement activation, however, have not been fully elucidated. The present BLI study demonstrated that the maximum response signals (capture levels) obtained by the use of HIK-M11 mAbs in the presence of $\mathrm{C}+$ (naïve serum) was 1.5 -fold higher than that obtained by the use of HIK-M09 mAbs (Figs. 2B, C). In addition, the study showed that HIK-M09 mAbs $\left(K_{\mathrm{D}}<0.001 \mathrm{nM}\right)$ have a much higher affinity for the PEG moiety compared with that of HIK-M11 mAbs $\left(K_{\mathrm{D}}=11.2 \mathrm{nM}\right)$ (Figs. 2B, C). These results suggest that the affinity of anti-PEG IgMs to immobilized PEG is not the only factor that mediates the activation of antiPEG IgM to the complement system. This issue is currently under intense investigation in our laboratory. Nevertheless, this in vitro alternative evaluation system should provide useful information that could be used to predict the in vivo fate of PEGylated products. The BLI system will allow us to study and determine whether the binding of anti-PEG IgMs in antiserum to immobilized PEGylated products then mediates a subsequent activation of the complement system, as shown in Figs. 1B and 2D. This occurrence is related to the extent of the in vivo clearance of PEGylated products via the $\mathrm{ABC}$ phenomenon. ${ }^{2,6-8)}$

In conclusion, in addition to the conventional methods (ELISA, Western blotting and hemolytic activity), we suggested a new approach that proved to be successful in evaluating anti-PEG IgM-mediated complement activation. This new method, BLI, is highly flexible and compatible, requires minimal sample handling, produces minimal background interference, and requires no chemical modification or cross-linking within a shorter time-frame. ${ }^{39)}$ In vitro assays using serum or plasma derived from experimental animals and healthy donor volunteers correlate with the in vivo complement-mediated re- actions, and therefore are helpful in predicting the in vivo fate of PEGylated products in basic research and clinical settings.

Acknowledgments This study was supported in part by a Grant-in-Aid for Transformative Research Areas (A) (Publicly Offered Research) (21H05526) and a Grant-in-Aid for Fostering Joint International Research (B) (19KK0279)) from the Japan Society for the Promotion of Science, by the Egyptian Government represented in the Cultural Affairs and Missions Sectors (Ministry of High Education), and by a research program for the development of an intelligent Tokushima artificial exosome (iTEX) from Tokushima University. The authors are grateful to Mr. James L. McDonald for his helpful advice in developing the English manuscript.

Conflict of Interest The authors declare no conflict of interest.

\section{REFERENCES}

1) Viana IMO, Grenier P, Defrêne J, Barabé F, Lima EM, Bertrand NJN. Role of the complement cascade in the biological fate of liposomes in rodents. Nanoscale, 12, 18875-18884 (2020).

2) Abu Lila AS, Kiwada H, Ishida T. The accelerated blood clearance (ABC) phenomenon: clinical challenge and approaches to manage. J. Control. Release, 172, 38-47 (2013).

3) Ishida T, Harashima H, Kiwada H. Liposome clearance. Biosci. Rep., 22, 197-224 (2002).

4) Ishida T, Kiwada H. Anti-polyethyleneglycol antibody response to PEGylated substances. Biol. Pharm. Bull., 36, 889-891 (2013).

5) Kozma GT, Mészáros T, Vashegyi I, Fülöp T, Örfi E, Dézsi L, Rosivall L, Bavli Y, Urbanics R, Mollnes TE, Barenholz Y, Szebeni J. Pseudo-anaphylaxis to polyethylene glycol (PEG)-coated liposomes: roles of anti-PEG IgM and complement activation in a porcine model of human infusion reactions. ACS Nano, 13, 9315-9324 (2019).

6) Wang L, Su Y, Wang X, Liang K, Liu M, Tang W, Song Y, Liu X, Deng Y. Effects of complement inhibition on the ABC phenomenon in rats. Asian J. Pharm. Sci., 12, 250-258 (2017).

7) Mohamed M, Abu Lila AS, Shimizu T, Alaaeldin E, Hussein A, Sarhan HA, Szebeni J, Ishida T. PEGylated liposomes: immunological responses. Sci. Technol. Adv. Mater., 20, 710-724 (2019).

8) Kozma GT, Shimizu T, Ishida T, Szebeni J. Anti-PEG antibodies: properties, formation, testing and role in adverse immune reactions to PEGylated nano-biopharmaceuticals. Adv. Drug Deliv. Rev., 154-155, 163-175 (2020).

9) Elsadek NE, Lila ASA, Emam SE, Shimizu T, Takata H, Ando H, Ishima Y, Ishida T. Pegfilgrastim (PEG-G-CSF) induces anti-PEG IgM in a dose dependent manner and causes the accelerated blood clearance (ABC) phenomenon upon repeated administration in mice. Eur. J. Pharm. Biopharm., 152, 56-62 (2020).

10) Hashimoto Y, Shimizu T, Mima Y, Abu Lila AS, Ishida T, Kiwada $\mathrm{H}$. Generation, characterization and in vivo biological activity of two distinct monoclonal anti-PEG IgMs. Toxicol. Appl. Pharmacol., 277, 30-38 (2014).

11) Mészáros T, Kozma GT, Shimizu T, Miyahara K, Turjeman K, Ishida T, Barenholz Y, Urbanics R, Szebeni J. Involvement of complement activation in the pulmonary vasoactivity of polystyrene nanoparticles in pigs: unique surface properties underlying alternative pathway activation and instant opsonization. Int. J. Nanomedicine, 13, 6345-6357 (2018).

12) Shimizu T, Awata M, Abu Lila AS, Yoshioka C, Kawaguchi Y, Ando H, Ishima Y, Ishida T. Complement activation induced by PEG enhances humoral immune responses against antigens en- 
capsulated in PEG-modified liposomes. J. Control. Release, 329, 1046-1053 (2021).

13) Shimizu T, Abu Lila AS, Fujita R, Awata M, Kawanishi M, Hashimoto Y, Okuhira K, Ishima Y, Ishida T. A hydroxyl PEG version of PEGylated liposomes and its impact on anti-PEG IgM induction and on the accelerated clearance of PEGylated liposomes. Eur. J. Pharm. Biopharm., 127, 142-149 (2018).

14) Kirschfink M, Mollnes TE. Modern complement analysis. Clin. Vaccine Immunol., 10, 982-989 (2003). doi: $10.1128 /$ CDLI.10.6.982-989.2003 Medline

15) Shimizu T, Ichihara M, Yoshioka $Y$, Ishida $T$, Nakagawa S, Kiwada H. Intravenous administration of polyethylene glycol-coated (PEGylated) proteins and PEGylated adenovirus elicits an anti-peg immunoglobulin M response. Biol. Pharm. Bull., 35, 1336-1342 (2012).

16) Hosseini S, Vázquez-Villegas $P$, Rito-Palomares M, Martinez-Chapa SO. Advantages, disadvantages and modifications of conventional ELISA. Enzyme-linked Immunosorbent Assay (ELISA): from A to Z. (Hosseini S, Vázquez-Villegas $\mathrm{P}$, Rito-Palomares M, MartinezChapa SO eds.) Springer Singapore, Singapore, pp. 67-115 (2018).

17) Kumaraswamy S, Tobias R. Label-free kinetic analysis of an antibody-antigen interaction using biolayer interferometry. Proteinprotein interactions: methods and applications. (Meyerkord CL, Fu H eds.) Springer New York, New York, NY, pp. 165-182 (2015).

18) Cooper MA. Optical biosensors: where next and how soon? Drug Discov. Today, 11, 1061-1067 (2006).

19) Meerasa A, Huang JG, Gu FX. CH50: a revisited hemolytic complement consumption assay for evaluation of nanoparticles and blood plasma protein interaction. Curr. Drug Deliv., 8, 290-298 (2011).

20) MacPhee DJ. Methodological considerations for improving Western blot analysis. J. Pharmacol. Toxicol. Methods, 61, 171-177 (2010).

21) Löfås S, Johnsson BJ. A novel hydrogel matrix on gold surfaces in surface plasmon resonance sensors for fast and efficient covalent immobilization of ligands. J. Chem. Soc. Chem. Commun., 1990, 1526-1528 (1990).

22) Pattnaik P. Surface plasmon resonance. Appl. Biochem. Biotechnol., 126, 79-92 (2005).

23) Wallner J, Lhota G, Jeschek D, Mader A, Vorauer-Uhl K. Application of Bio-Layer Interferometry for the analysis of protein/liposome interactions. J. Pharm. Biomed. Anal., 72, 150-154 (2013).

24) Dasa SSK, Diakova G, Suzuki R, Mills AM, Gutknecht MF, Klibanov AL, Slack-Davis JK, Kelly KA. Plectin-targeted liposomes enhance the therapeutic efficacy of a PARP inhibitor in the treatment of ovarian cancer. Theranostics, 8, 2782-2798 (2018).
25) Do T, Ho F, Heidecker B, Witte K, Chang L, Lerner L. A rapid method for determining dynamic binding capacity of resins for the purification of proteins. Protein Expr. Purif., 60, 147-150 (2008).

26) Concepcion J, Witte K, Wartchow $\mathrm{C}$, et al. Label-free detection of biomolecular interactions using BioLayer interferometry for kinetic characterization. Comb. Chem. High Throughput Screen., 12, 791-800 (2009).

27) Fjorback AW, Varming K, Jensen HP. Determination of $\alpha$-synuclein concentration in human plasma using ELISA. Scand. J. Clin. Lab. Invest., 67, 431-435 (2007).

28) Lachmann PJ. Preparing serum for functional complement assays. J. Immunol. Methods, 352, 195-197 (2010).

29) Ishida T, Wang $X$, Shimizu T, Nawata K, Kiwada H. PEGylated liposomes elicit an anti-PEG IgM response in a T cell-independent manner. J. Control. Release, 122, 349-355 (2007).

30) Suzuki T, Ichihara M, Hyodo $K$, Yamamoto E, Ishida $T$, Kiwada $H$, Ishihara H, Kikuchi H. Accelerated blood clearance of PEGylated liposomes containing doxorubicin upon repeated administration to dogs. Int. J. Pharm., 436, 636-643 (2012).

31) Bartlett GR. Colorimetric assay methods for free and phosphorylated glyceric acids. J. Biol. Chem., 234, 469-471 (1959).

32) Fortebio. "Biosensor selection guide." 〈http://www.fortebio.com/ literature.html, accessed 17 February, 2021.

33) Soltis RD, Hasz D, Morris MJ, Wilson ID. The effect of heat inactivation of serum on aggregation of immunoglobulins. Immunology, 36, 37-45 (1979).

34) Walport MJ. Complement. First of two parts. N. Engl. J. Med., 344, 1058-1066 (2001).

35) Walport MJ. Complement. Second of two parts. N. Engl. J. Med., 344, 1140-1144 (2001).

36) Abu Lila AS, Ishida T. Liposomal delivery systems: design optimization and current applications. Biol. Pharm. Bull., 40, 1-10 (2017).

37) Fante MA, Decking S-M, Bruss C, Schreml S, Siska PJ, Kreutz M, Renner K. Heat-inactivation of human serum destroys $\mathrm{C} 1$ inhibitor, pro-motes immune complex formation, and improves human $\mathrm{T}$ cell function. Int. J. Mol. Sci., 22, 2646 (2021).

38) Osmand AP, Mortensen RF, Siegel J, Gewurz H. Interactions of C-reactive protein with the complement system. III. Complementdependent passive hemolysis initiated by CRP. J. Exp. Med., 142, 1065-1077 (1975).

39) Fortebio. "Aminopropylsilane (APS) Biosensors (kinetics grade) for hydrophobic immobilization of proteins." 〈http://www.fortebio.com/ literature.html>, accessed 17 February, 2021. 